\title{
Interactive Drilling: The Up-To-Date Drilling Technology
}

\author{
O. Vincké ${ }^{1}$ and C. Mabile ${ }^{1}$ \\ 1 Institut français du pétrole, 1 et 4, avenue de Bois-Préau, 92852 Rueil-Malmaison Cedex - France
}

Résumé - Le forage interactif : la technologie de forage d'aujourd'hui - Les technologies de forage ont fait beaucoup de progrès durant ces vingt dernières années. Dans le passé, le développement d'un champ nécessitait le forage de nombreux puits. Les premiers servaient à l'exploration et à l'évaluation du champ.

Aujourd'hui, le forage de puits horizontaux ou de puits avec des géométries complexes se fait couramment. Les puits ERD (Extended Reach Drilling) permettent d'atteindre des réservoirs éloignés.

Le forage est une occasion unique d'acquérir des données afin de prendre des décisions en temps réel menant à une optimisation globale de la productivité du puits.

Toutes les nouvelles technologies, forage, acquisition et transfert de données, moyens de calcul rapide donnent l'occasion de fournir au géologue, à l'ingénieur de réservoir et au foreur l'information précise pour prendre de meilleures décisions. Des nouveaux outils doivent être conçus pour permettre une utilisation optimisée de cette information.

Les données doivent être transformées en une information utilisable afin que des décisions puissent être prises rapidement avec un faible niveau de risque. En outre, il reste la nécessité de faire l'évaluation économique en temps réel du puits de sorte que la décision de poursuivre le forage ou non soit également prise en cours de forage.

Dans ce dossier, différentes techniques utilisées dans le forage seront discutées. Ce sera aussi l'occasion d'illustrer des résultats de projets de recherche réalisés par l'IFP et ses partenaires.

Abstract - Interactive Drilling: The Up-To-Date Drilling Technology - Drilling technologies have made much progress the last twenty years. In the past, many wells had to be drilled before and during the development of an oil field. The first wells were devoted to exploration and appraisal and the following ones to development of the oil field.

Today, with horizontal drilling a common technique, wells with complex geometry can be drilled in a reservoir allowing the oil to be extracted from different places. Extended reach wells allow oil from remote locations to be reached.

Furthermore, capitalizing on drilling is an efficient way to reduce the costs of appraisal, development and exploitation of an oil or gas field. Drilling is a unique opportunity to acquire data in order to take real time decisions leading to a global optimization of the drainage system.

All the new technologies such as measurement while drilling, data acquisition, data transfer or high speed computing give the opportunity to provide the geologist, the reservoir engineer and the drilling engineer with more accurate information for taking better decisions. However new tools have to be designed to allow an optimized use of this information. Raw data must be transformed to high level of information so that decisions can be taken quickly with a low level of risk. However there is still the need 
to perform real-time economic evaluation of the well so that the decisions to drill one meter more can be also taken on economic simulations.

In this revue, different techniques to generate high quality information from drilling data will be discussed. Some results issued from research projects managed by IFP and its partners will be addressed.

\section{FOREWORD: INTERACTIVE DRILLING AND GEOSTEERING}

Geosteering can be defined as a particular highly interactive work process between different disciplines in planning and drilling the different phases of a well.

The aim of geosteering is to obtain an accurate well location in the reservoir to maximize the well productivity. It is more particularly dedicated to the steering of horizontal drains.

Geosteering is carried out using tools and well techniques that allow to:

- acquire the data (surface and downhole) in real time with bi-directional telemetry;

- process, analyze and interpret the data during the drilling process;

- interpret/estimate/visualize while drilling on remote sites;

- update the geological model and the well path according to the processed data;

- pilot the well.

Interactive drilling includes all techniques which aim to improve the drilling of the well. Therefore, geosteering is included in unteractive drilling but interactive drilling includes also processes such as alarms on drilling parameters, drillpipe fatigue estimation or well bore stability.

\section{INTRODUCTION [1]}

Drilling technologies have much progress the last twenty years. Before, to develop an oil field, many wells were drilled. The first ones were devoted to exploration and appraisal and the following to development of the oil field. The choice of the drilling technique had no real impact on the capital expenditure.

Now, horizontal drilling is a common technique, wells with complex geometry can be drilled in a reservoir allowing the oil to be extracted from different places. Extended reach wells allow oil from remote locations to be reached. All these new technologies are now available and at a reasonable cost.

This is due to three following major breakthroughs.

\subsection{Directional Drilling Technology}

The improvement in mud motors and in PDC bits (polycrystalline diamond cutter) have been the key points.
Mud motors with a bent housing allow the well to be steered accurately towards the target. With PDC bits the time to drill the well is greatly reduced. However steering is done with no drillpipes rotation (sliding mode) with, as a consequence, higher risks and a slower rate of penetration (ROP).

In the middle of the 1990's, the appearance of the rotary steerable systems (RSS) allows a combination of the advantages of the two traditional techniques: the precision of mud motors and performance of the rotary drilling. This technology reduces the risk of stuck pipes by better hole cleaning and increases the ROP by better weight transfer to the bit and a smoother well path.

\subsection{Measurements while Drilling}

Not only the drilling technology but also the gathering of data while drilling has made progress. Since its introduction in the mid seventies, computerized mud logging services have continuously improved to contribute to an optimization of the drilling process in terms of safety and cost savings. Online monitoring of key parameters is backed by the use of a relational database ( $v s$ time and $v s$ depth) which enables offline work on the main drilling events recorded (such as tripping or cementing) in relation to the geological context. This opens up large possibilities for the interpretation of parameters in real-time while drilling or tripping, and for correlation with other wells.

In a complementary way, measurement while drilling (MWD) became logging while drilling (LWD) and finally formation evaluation while drilling (FEWD). MWD allows the current trajectory of the well to be determined. LWD gives in front of different sensors some measurements such as resistivity or gamma ray. FEWD is a complete set of tools which allows most of the reservoir properties such as shale content or porosity to be measured.

With the information coming from directional drilling measurements, mud logging and LWD/FEWD tools the drilling engineer can react more and more rapidly to a problem and correct the well path if necessary.

\subsection{Computer Technology and Imaging}

From another viewpoint, information can now travel around the world at the speed of light and a rig can be connected to the offices to exchange information whatever their location in the world. The computers are faster and faster and their cost is still staying at an acceptable level. 
All these new technologies, drilling, data acquisition, data transfer and high speed computing give the opportunity to provide to the geologist, the reservoir engineer and the drilling engineer more accurate information for taking better decisions. However, new tools have to be designed to allow an optimized use of this information. Data must be transformed to high level information so that decisions can be taken quickly with a low level of risk. Furthermore, there is still the need to perform real time economic evaluation of the well so that the decisions to drill one meter more can be also taken on economic simulations.

\section{THE EXISTING PROCESS OF DECISION MAKING WHILE DRILLING}

\subsection{Distribution of Information}

Thanks to modern computerized mud logging unit (Fig. 1) at the well site, accurate, real time information is available to everyone who needs it (tool pusher, drilling engineer, geologist, drilling engineer, mud engineer) through interactive workstations (Fig. 2).

Anyone with a workstation can follow the progress of operations in real time, enabling everyone to stay informed and to work together efficiently and in greater safety. They can also interrogate the database and examine sections of interest in a variety of different graphic presentations. Multireference, multi-well display capabilities mean that data can be displayed simultaneously during drilling or tripping, with reference to different criteria (depth, time, lagged depth) either from the current well or from other previously-stored wells. Assistance is therefore provided to the drilling engineer for many tasks such as optimization of hydraulic parameters, cement job calculations, well-control contingency plans and daily reporting. These same real time and interactive capabilities are available to any similar workstations employed in distant offices, and connected through the operating company's own telecommunications network.

\subsection{Early detection of Abnormal Events}

The driller obviously has to react quickly to events if abnormal situations arise. On the drill floor, the rig floor computer will automatically warn the driller in due time of any abnormal situations. Proposed as "add-ons" to the standard unit, these applications are very cost-efficient compared to the benefits gained, since the crew can make immediate corrective action. The key to such a system is the implementation, on a dedicated workstation, of special processing software that extracts a corrected signal from the raw output of sensors. This signal, which takes into account not only the present sensors output, but also constantly updates typical rig/well responses, will automatically trigger a drilling floor alarm and/or display. Drill string vibrations monitoring [2, 3, $4,5]$ and advanced kick detection [6, 7] are the first topics which have been addressed. Research and development programs have been set up through IFP and Geoservices in order to improve the scientific background of the algorithms used by this processing software and to enhance their detection capabilities. Current computation availability on board allows the implementation of more and more sophisticated models. The challenge is to stay in line with the necessity to output quickly, without the intervention of a dedicated

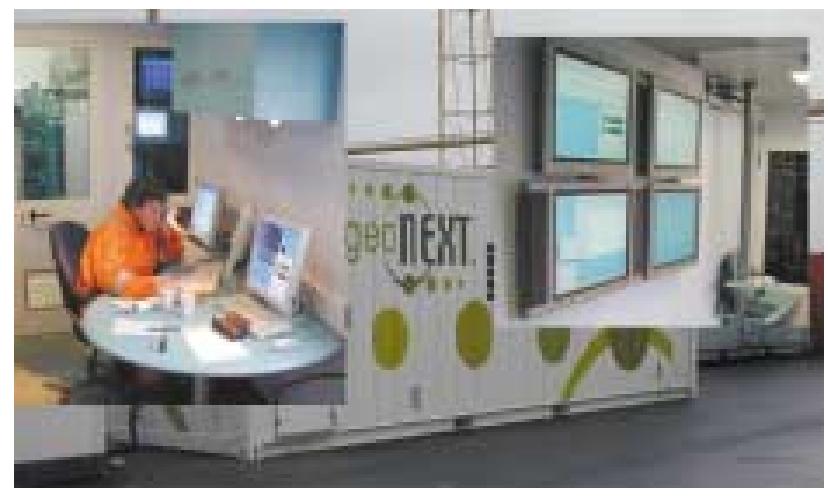

Figure 1

Mud logging unit.

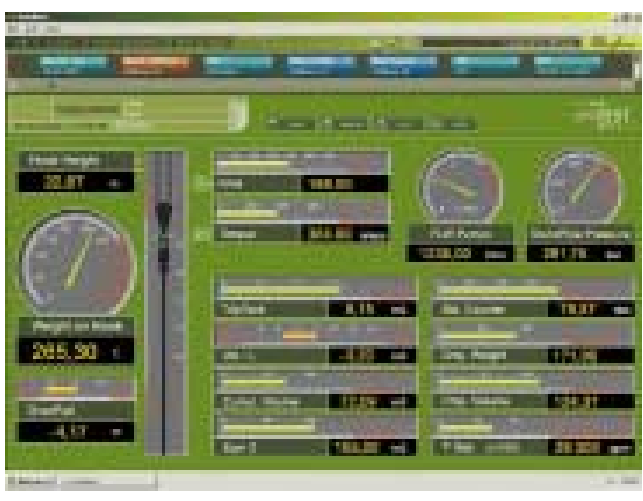

Figure 2

Workstation. 
operator, a reliable and understandable alarm signal which can be used by the drilling crew.

\subsection{Adjusting the Drilling Program During the Drilling Process}

The process of taking decisions regarding the drilling program while drilling is generally as follows:

- the targets given to the drilling engineer are defined using information gathered from previous wells;

- the drilling program is defined using these targets taking into consideration the results of the previous wells;

- while drilling there are almost no possibilities to update the geological or the reservoir model;

- the drilling engineer has no access to these models while drilling and therefore has a little knowledge of what is around the well.

This can be summarized in the following graph (Fig. 3).

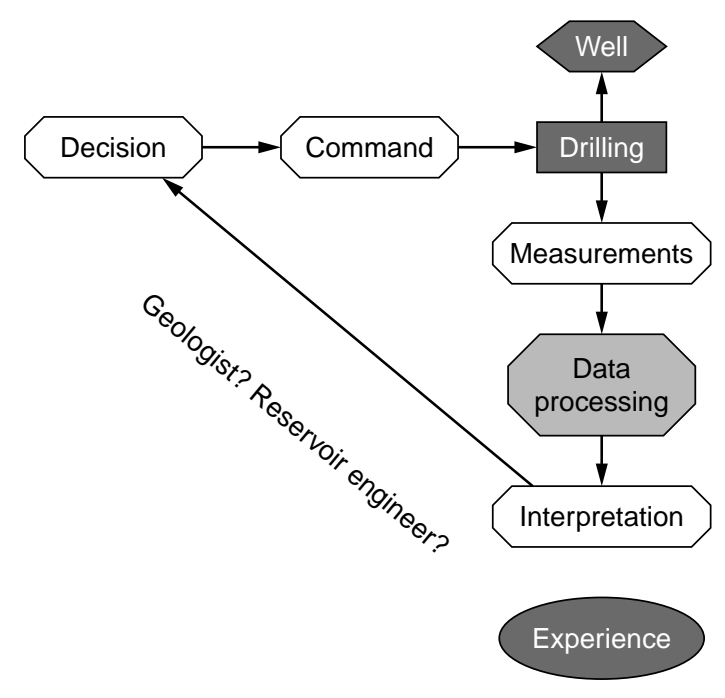

Figure 3

Today's drilling loop.

The drilling process generates information which is detected through the sensors used in mud logging and in logging while drilling. In most of the cases these data are used directly by the drilling engineer to make his decisions and thus on the basis of his experience. However sometimes these data are processed either on line or off line to generate information which is delivered to the drilling engineer to take his decisions.
It must be noticed that the drilling engineer can play only on a few parameters due to technical feasibility or availability of equipment. They are:

- drilling parameters (WOB, RPM, bit, BHA and mud flow rate);

- mud characteristics (mainly its density);

- casing setting point;

- well path.

We can summarize this process for taking decisions while drilling by saying that it is rig driven: operations are going faster than the ability of the industry to update the models on which the well planning has been based. Therefore, most decisions are taken on the rig floor with the sole data and information provided by the surface and downhole measurements, with very limited interactions with the previous engineering planning phase.

However, with the development of the distribution of information and of visualization techniques, the information gathered on the rig site can be distributed in real time to various people such as the geologist or the reservoir engineer in different sites or in the same office.

These people together with the drilling engineer can interact to take better decisions but generally this is not done on the rig site and the on site drilling personnel are out of this process.

\section{GENERATING INFORMATION FROM THE DRILLING: REVIEW OF SOME IMPORTANT TECHNICAL ISSUES}

On site real-time data aid in oilfield development: many case histories have demonstrated how the use of rig site data acquisition computers provides well-site geologists and drilling engineers with valuable data from which rapid and efficient decisions could be made at the rig site. One more step is needed: to process, analyze and interpret the rig site data in real time so as to obtain valuable information which will be used during the whole life of the oil field asset by all kinds of engineers and geoscientists.

\subsection{Getting Information from the Drilling Fluid}

To drill a well, the usual practice consists in destroying the rock with a tricone or a PDC bit. The drilling fluid is injected inside the drill string to the bit and rises in the annular back to the surface. The mud circulation during drilling has multiple objectives such as bit cooling, hole cleaning, or borehole stability.

The drilling fluid travelling back from the bit in the annulus brings back to the surface many indices from the formation being drilled. Much valuable data is contained in the cuttings $[8,9]$ and in the gas. Despite the lag time, the 
time taken by the mud to travel from bottom to surface, this information is the first that the geologist will have to get a direct look at the formation being drilled and of the gas contained in the reservoir.

However to obtain and interpret correctly these data it is necessary to have a good understanding and thus a good model of the downhole conditions. IFP has developed many procedures to estimate different downhole parameters from surface measurements.

A good example of these procedures is the estimation of the pressure profile in the annulus. This pressure is characteristic of the drillpipe geometry, the annular geometry, the bit nozzle geometry, the mud rheology and so on. Having a correct estimate of the pressure profile in the annulus is very important for the safety of the well. Too low a pressure gives rise to kick or well collapse, too high a pressure can generate fracture.
The estimation of the pressure profile (Fig. 4) in the well can also help to generate information about the pore pressure in the drilled formations. A good example is the gas generated each time the circulation is stopped when the mud density is well adjusted to the pore pressure.

However, computing exactly the equivalent circulating pressure (ECD) needs good knowledge of the temperature profile and of the variations of the mud rheology with the temperature and the pressure.

IFP has developed a procedure that, from measurement of in and out and bottom hole temperature at surface, will estimate the temperature profile all along the well.

Once the temperature profile has been estimated, a database is used to update the mud rheology along the well. Mud rheology is function of pressure and temperature. We have developed a database, which allows the mud rheology
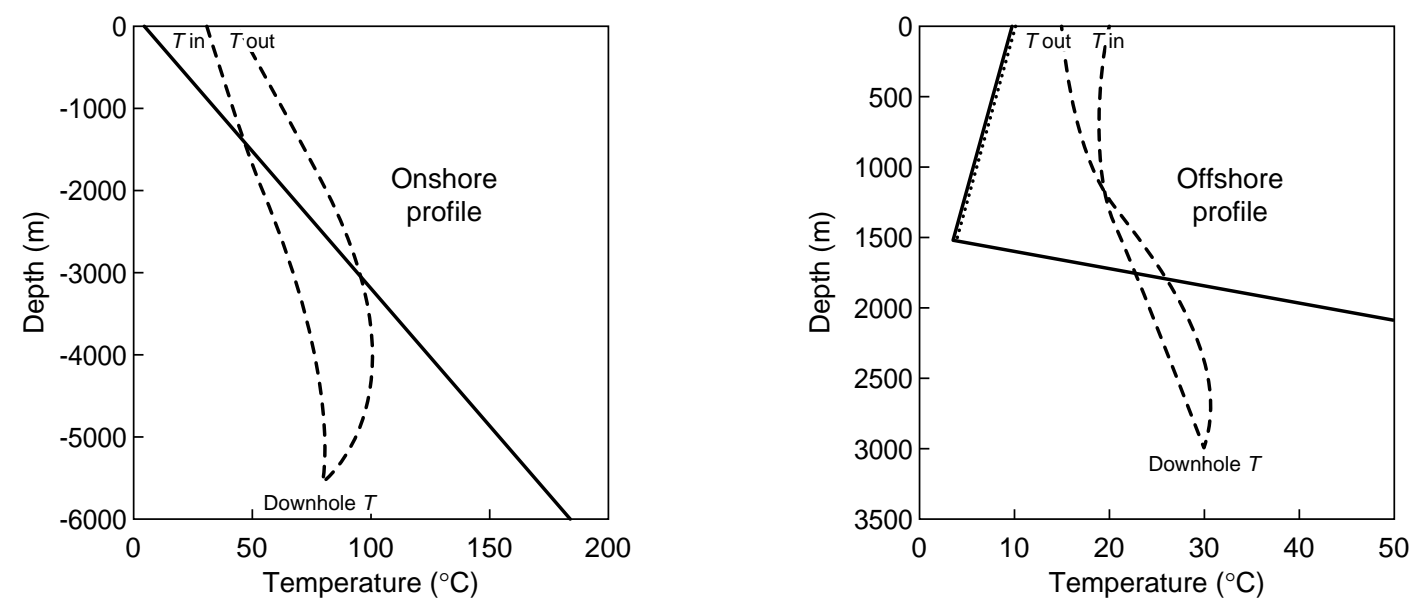

Figure 4

Onshore and offshore temperature profile.

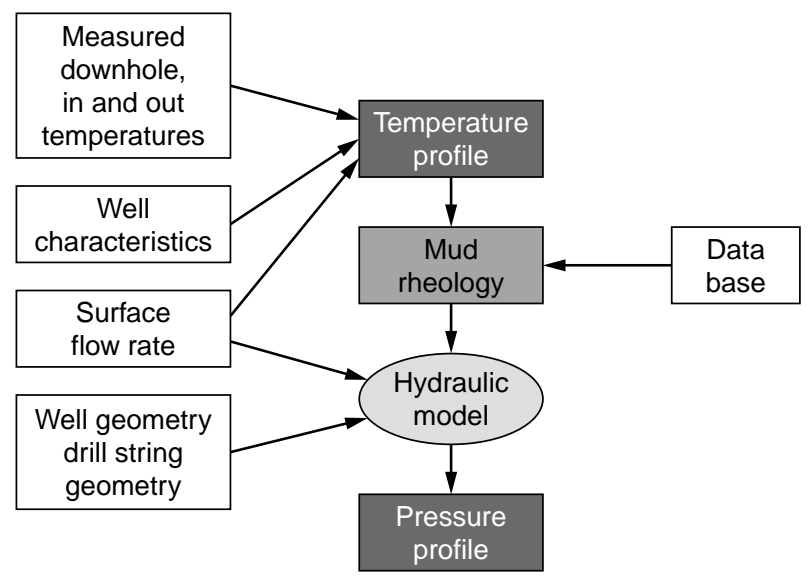

Figure 5

Work flow to pressure profile computation. 
to be estimated at any pressure and temperature from measurements at atmospheric pressure and room temperature (Fig. 5).

Then the pressure profile is computed using a hydraulic model taking into account pipe eccentricity and rotation.

IFP with Geoservices has used this modeling to detect earlier the appearance of events in the well from a variation of the stand pipe pressure. One of the obstacles to the use of this stand pipe pressure as an unique indicator, is the fact that a change of this pressure may be due to a variation of the mud flow rate, its density, or its viscosity, etc. a real time intelligent rig-site diagnosis system has been developed, which can detect different malfunctions of the hydraulic system in steady state, taking into account several sensors and information generated by models.

\subsection{Getting Better Data from the Gas Contained in the Mud}

Continuous monitoring of gas content in the mud can lead to an optimization of the drilling process, such as mud density adjustment to pore pressure, but also improved real time reservoir evaluation. This allows geological and drilling personnel onsite to determine more easily the tops of reservoirs, to locate gas-bearing marker zones, and even to "steer" directional well bores along thin reservoir beds $[10,11]$.

Recent improvements by IFP and Geoservices have been made on the system itself (high speed-high accuracy chromatograph coupled with constant volume-high efficiency degassing device) but also on the processing of the data. These improvements have dramatically reduced the effects of variables such as mud density, viscosity and flow rate on the degassing of the mud. Gas readings can be accurately corrected for degassing efficiency or recycled gas. Trip and connection gas which also provide indications of the combined effect of pore pressure and permeability are detected with better accuracy. That means that the relative gas composition provided at surface gives a much better indication of the actual composition of gas in situ in the reservoir.

\subsection{Evaluation of Rock Mechanical Properties from Drilling}

Stability of underground excavations is the oldest but also the most common engineering problem in drilling. The objective of any calculation is to size a propping agent. The mud density normally ensures hole stability. This problem is today recognized as a major engineering challenge when drilling complex wells. Stresses, pore pressure and rock strength are the major parameters governing the wellbore stability.

Drill bit manufacturers must design the bit considering different criteria: economics, ROP, durability, or steerability. It is very important that they have a good evaluation of the rock strength. Using this knowledge in the design of their bit, they increase cutter wear and impact resistance, and provide extended bit life with improved performance for improved drilling economics.

Through these two examples, one can note the importance of the rock mechanical properties for well planning.

The "geomechanical log" is a research project in progress at IFP. The object is to define software based on a set of models, which will allow rock mechanical properties to be estimated from their porosity, mineralogical content, etc. Model input data will be deduced from drilling logs (the final methodology remains to be precisely defined) and core samples (if some are available). The properties sought after are: poroelastic properties (bulk and shear moduli, Biot coefficient and Biot modulus), yield criteria and plastic flow laws, failure criteria (shear failure and cap surface). The predicted rock properties will provide input data for any drilling model, wellbore stability software, etc., and will help to optimize drilling.
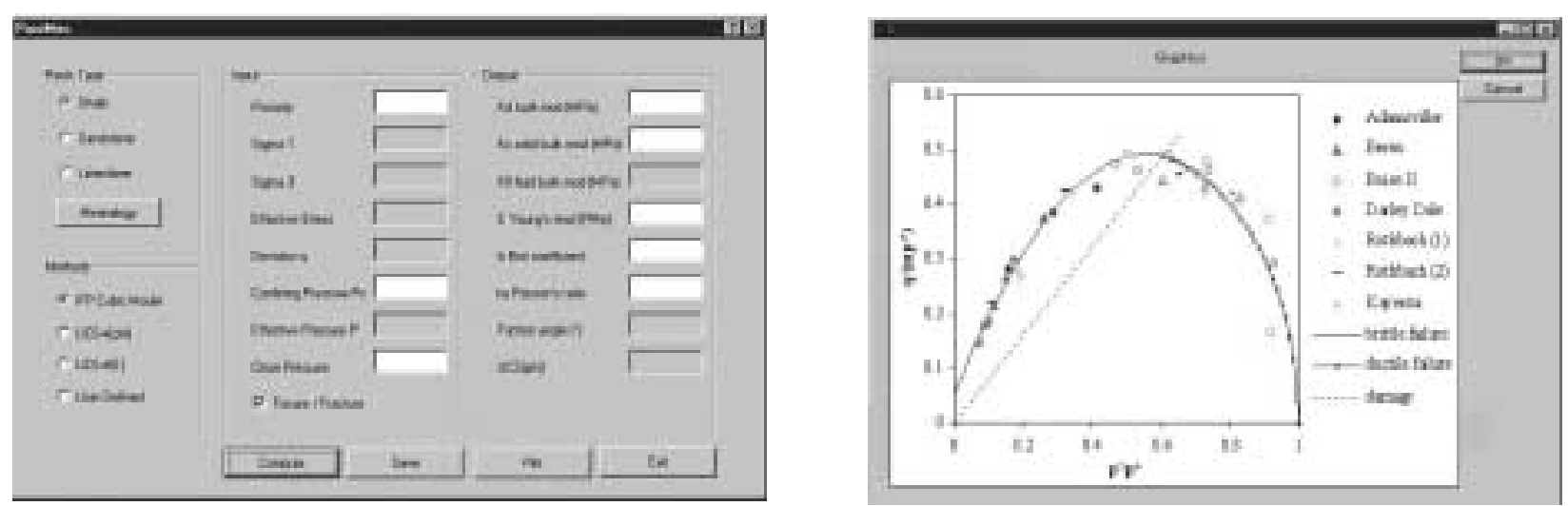

Figure 6

Rock mechanical software. 
Software (Fig. 6) has been developed to compute the mechanical properties. Figure 6 gives an example of the defined models. The failure data are normalized by the grain crushing pressure $p^{*}$, which corresponds to the failure pressure under hydrostatic loading.

Further data, both from logs and lab results on core samples, are required to improve the models. Investigation on shales is in progress.

\subsection{Drill Bit Seismic Method and VSP While Drilling}

Up to now all the measurements or observations gathered while drilling bring information located in the vicinity of the well. Surface mud logging or down hole logging while drilling are unable to provide information on the rocks and fluids properties farther than a few feet away from the walls of the well and no information of what is ahead of the bit.

To look ahead of the bit the only techniques available today are the seismic while drilling ones:

- drill bit seismic method while drilling (DBS-WD) (Fig. 7) using the bit as a seismic source;

- vertical seismic profile while drilling (VSP-WD) using a standard surface seismic source.

DBS-WD uses the bit as a seismic source. The bit (mainly the three-cone type) generates vibrations when drilling. These vibrations travel up and down in the formations and can be recorded at the surface through geophones. As the bit is not a correlated seismic source recording at surface is not effective. Therefore it is necessary to record down hole almost continuously the noise generated by the bit. At surface arrays of geophones will record the seismic signals generated by the drilling bit and their reflections on different formations. Therefore synchronization is necessary between the surface and the down hole recorder.

The VSP-WD uses a standard seismic source located at surface. A geophone is located just above the bit in a specific downhole tool. The seismic vibrations generated at surface are recorded down hole. However, synchronization is also necessary between the surface and the downhole recorder, in order to compute correctly the time the seismic vibrations took to travel from surface to downhole.

In the two seismic while drilling techniques (DBS and VSP-WD) synchronization (using electromagnetic transmission developed by Geoservices or a stabilized clock) is therefore necessary between the surface and downhole recorders.

Geoservices [12, 13] had developed a prototype for each kind of seismic while drilling technique with memory capacity large enough to record all the necessary data during drilling. Tests have been done in different wells and below we will present a case of using the DBS-WD (Fig. 8).

On this site the standard seismic technique is not effective and no reflectors can be seen. The DBS-WD was used during the drilling of $150 \mathrm{~m}$ and with 6 lines of geophones set at the surface around the well. After having downloaded the recorded data to the computer and processed them, a 3D seismic profile was generated. The left view represents a cross section of this $3 \mathrm{D}$ profile. As the bit is a punctual seismic source, the illuminated zone has a cone like shape starting from the point where recording started. For the same reasons there is a blanking zone along the bit axis. However seismic reflectors can be clearly located under the bit and as far as $1000 \mathrm{~m}$ below the bit whereas no real reflectors can be located using the surface seismic.

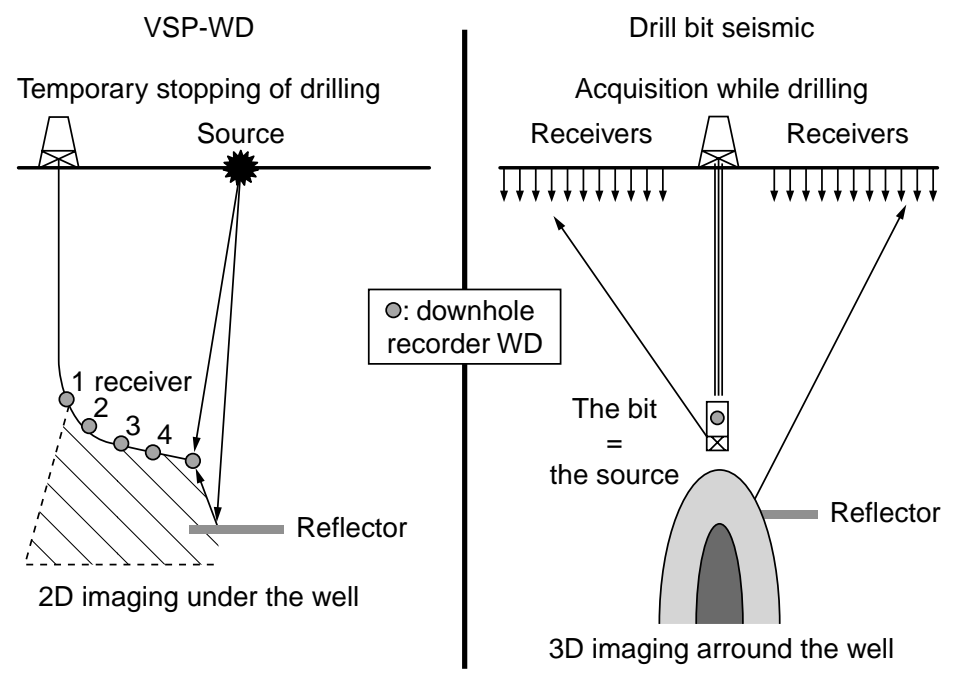

Figure 7

VSP-WD and DBS-WD techniques. 

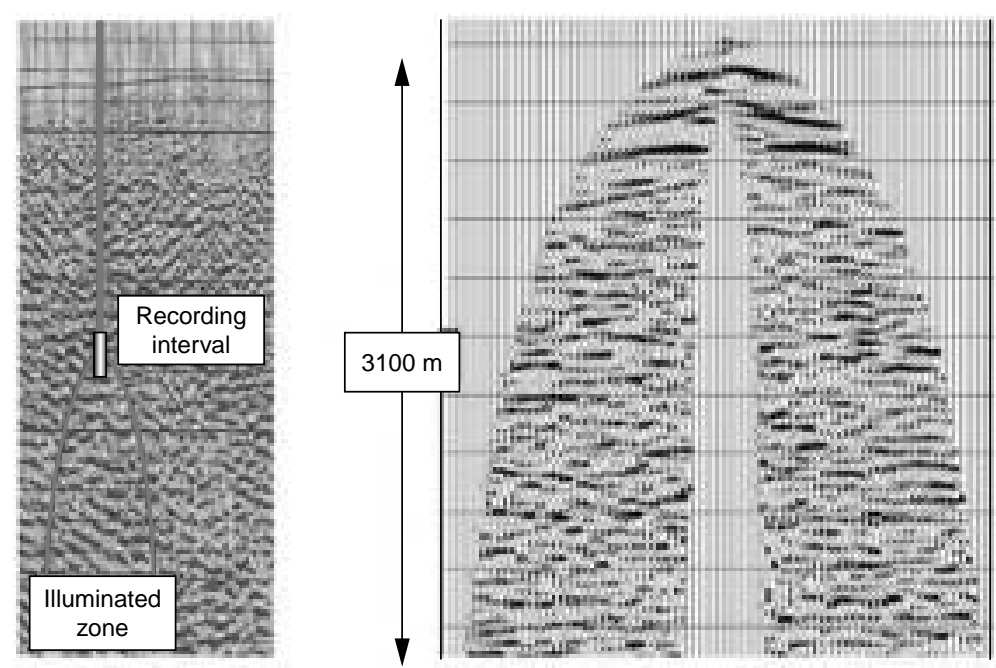

Figure 8

DBS-WD: a case study.
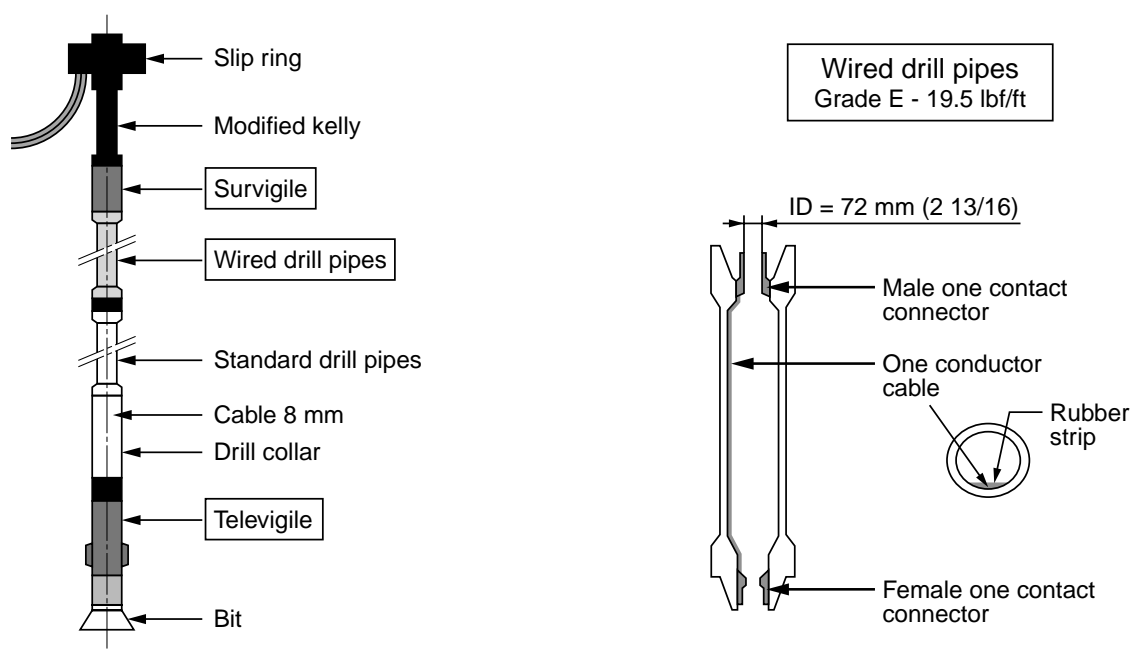

Figure 9

Trafor-X system.

The DBS-WD and the VSP-WD will allow the seismic profile to be updated ahead of the bit. It will be possible to locate the bit on the seismic profile and thus to modify accordingly the trajectory of the well. Through the inversion from time to depth, the geological and thus the reservoir model will be corrected during drilling using this new information.

\section{DOWNHOLE TO SURFACE DATA TRANSMISSION}

The drilling industry has made some quite extraordinary improvements with very limited telemetry from downhole tool powered by batteries. Current mud pulse telemetry is limited to 8 to 10 bits/s. Electromagnetic technology provides data rates of up to $100 \mathrm{bits} / \mathrm{s}$. Real time data transmission is more and more accepted. The evolution of drilling technologies and the real-time processing require high-speed transmission.

The development of an electric drillstring could be have two advantages: to have electrical power downhole and to have a high-speed data transmission from downhole to surface. It could reduce cost by replacing wireline logging with real time LWD systems, with improved well productivity from improved geosteering via immediate feedback from the high quality telemetry path (SWD, LWD, etc.). It could allow the development of new sensors and new tools. 
An MWD system called Trafor-X [3, 4] (Fig. 9) has been developed some years ago by IFP for the acquisition of downhole and surface sensors at high speed. It can scan, send and store synchronized data from 24 channels while drilling. The system has been used on many locations during specific drilling and geophysics projects. This led to the creation of a large database which includes many hours of high level vibrations of the drill string, such as stick slip, bit bouncing and whirling. The Trafor-X system is made of two subs (televigile, survigile) for measuring many real time downhole and at surface parameters and of an electrical link between downhole and the surface to transmit the real time data at high rate (wired drillpipes). This system was a research tool and has not been industrialized. It has allowed development of an approach from surface measurements for the detection of vibrations generated downhole.

$B P$ and Weatherford [14] have started the development of an "Electric Drillstring ${ }^{\mathrm{TM}}$ ". This system should enable electric power to be transmitted through the drillpipe while simultaneously multiplexing data back to surface from the downhole system. Only feasibility phases have been done. The main part of these phases has been the development of a reliable electrical connector integrated into a premium drillpipe thread that will behave like a normal tool-joint during operation.

Grant Prideco [14, 15] has developed an advanced telemetry system called Intellipipe ${ }^{\mathrm{TM}}$. This system provides complete, real-time downhole drilling and LWD data transmission (1 $000000 \mathrm{bits} / \mathrm{s}$ data transmission) and allows real-time bidirectional communication. This system requires no special handling or make-up procedures. It has been tested with success in laboratory and in real conditions. Electric connection is in fact an inductive one without any contacts. Therefore reliability is high but periodic transmitters are necessary.

\section{IMPROVING THE DECISION MAKING PROCESS WHILE DRILLING}

Up to now, the drilling engineer is almost the sole user of the data acquired while drilling. The onsite geologist uses some of these data to generate the master log but he seldom participates to the decision process.

The design and drilling of advanced wells, such as extended reach wells, horizontal wells and multilateral wells, has forced operators to break down the traditional barriers between drilling and geophysical disciplines. One can notice a growing need for new multidisciplinary software platforms to assist in the planning and the drilling of complex wells.

In the new decision process that is emerging the geologist and the reservoir engineer will use the information generated by the drilling to update their geological or reservoir models. Therefore, the drilling must generate information that can be used directly by the software handling the geological or reservoir models. A direct link is created between the system on the rig site generating the information and this software. The role of the geologist and of the reservoir engineer is to use this information to validate or not the updating of the models.

\subsection{Integrating the Geologist and the Reservoir Engineer in the Decision Process}

Virtual systems called Cave (Fig. 10) have been developed by different societies for a better planning of complex wells. The system allows to visualize data in a virtual 3D environment. The user (drilling engineer, geologist, geophysicist, and reservoir engineer) can manipulate and interact with the data. The integrated team is virtually immersed in the reservoir and the well paths can be adjusted interactively in virtual geology.

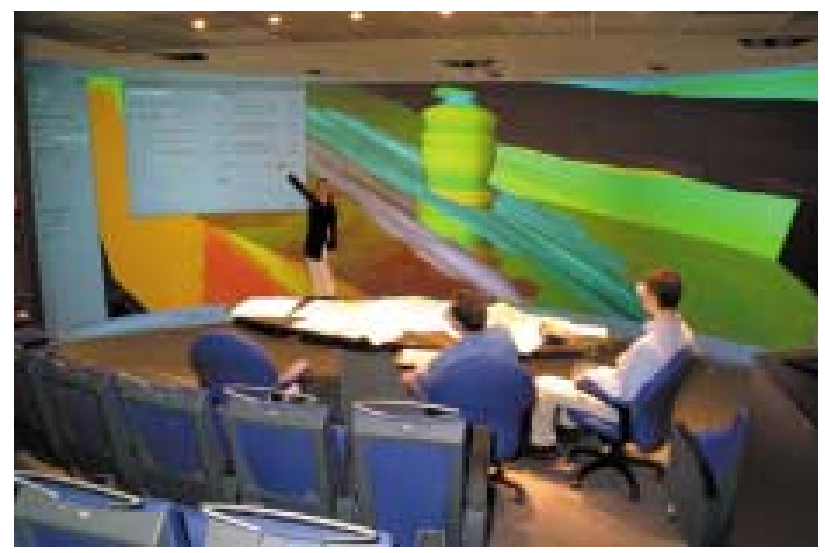

Figure 10

An example of Cave.

In Section 3, the decision making process as it is today have been described. We have seen that the geologist is very seldom included and the reservoir engineer almost never.

However the drilling industry needs to include to an ever greater extent the geologist and the reservoir engineer in the decision tree as the well is being drilled. Most the newly discovered reservoirs are complex. A good example of this complexity is reservoirs made of many small highly productive zones amongst nonpermeable layers.

As an illustration, in 2001 Sincor [16], an operating company, used real-time logging-while-drilling for its field development program in eastern Venezuela. Real-time data (surface and downhole) were transmitted via satellite to headquarters in Caracas $(300 \mathrm{~km})$. The survey information (inclination and azimuth), and the logging-while-drilling 
information were for the first time directly loaded into a Landmark Graphics Openworks ${ }^{\mathrm{TM}}$ database. The well trajectory could then be viewed on the seismic profile. With this information, the geoscience team members made betterinformed decisions, such as redefining the well trajectory.

On an other hand, the investments cost necessary to produce new reservoirs are more and more important because these reservoirs are in remote zones, deep offshore or contain low quality oils. Therefore, to make the investments profitable it is necessary that the wells drilled in these new reservoirs reach a very high production level over a long duration.

This double objective of high production and high recuperation can be reached only if the well drilled in the reservoir intersects the maximum of productive zones. In most cases, the reservoir description is not accurate enough to reach this objective and needs to be refreshed while the well is being drilled. This is why we need to have the geologist and the reservoir engineer to interact with the geological and reservoir model on the basis of the information provided by the drilling activity.

By integrating, the geologist and the reservoir engineer in the data loop (Fig. 11), the drilling engineer will now have an updated knowledge of the geology of the reservoir. A production simulation using a subset of the reservoir model in the vicinity of the well path may help to identify the production zones. On the basis of this information, the integrated team including geologist, geophysicist and driller can take better decisions such as going on drilling, changing the well path, drilling a new branch or stopping and completing the well.

\subsection{New Loops for Onsite Decisions}

We now can define new loops (Fig. 12) for onsite decisions.

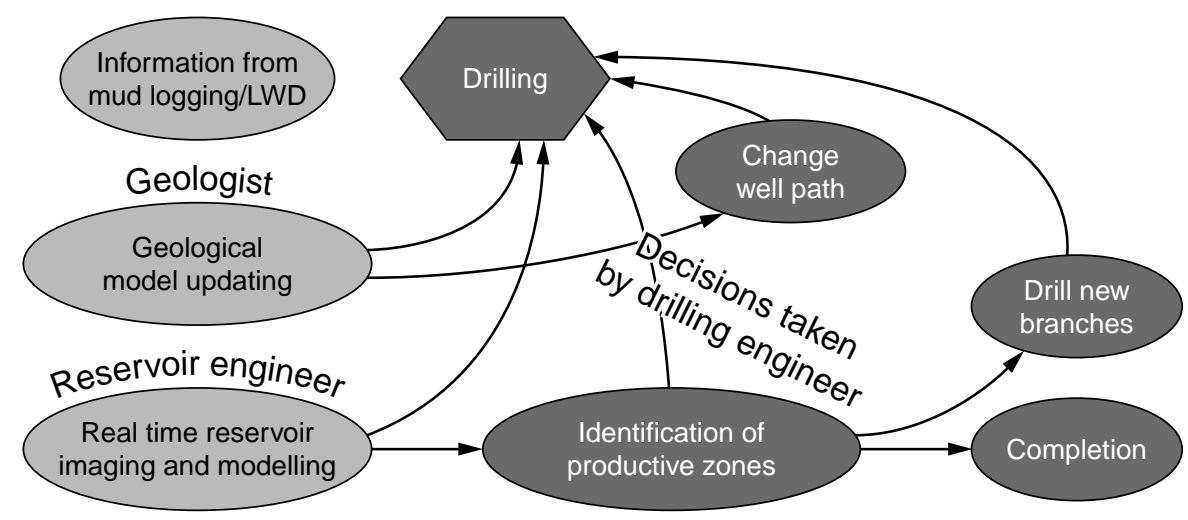

Figure 11

New loop integrating geologist and reservoir engineer.

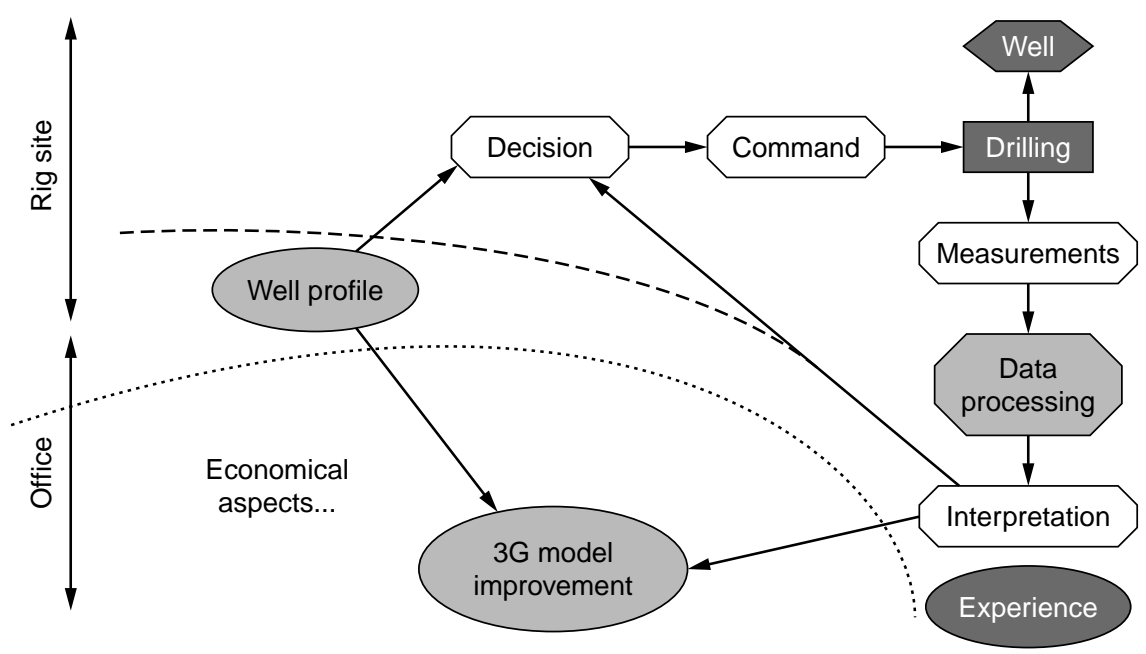

Figure 12

New loops for on site decisions. 
In these loops the data generated either by the mud logging or the logging while drilling are processed to generate information that can be used directly by the drilling engineer, the geologist or the reservoir engineer. Using specific software the geological model is updated or a new reservoir simulation is done during drilling and targets to be reached by the well are better defined. This provides the drilling engineer with new information to take better decisions on the well path.

\subsection{The WOG (Well Optimization by Geosteering) Project}

Today IFP has started to develop a new data management system named WOG.

In this project, we want to distribute the information through the network (Fig. 13) to share the knowledge. The great potential of the software is to allow visualization for each business. So, the driller will have the view that he uses currently, the geophysicist will have the view that he is used to, and so one for each discipline.

WOG uses two recent developments: 3D Geopilot and Episem.

The 3D Geopilot is a software that computes parametric links between the different layers and faults to allow future updating during the drilling process.

Using the 3D Geopilot, the geologist and geophysicist engineers could start from classical workstation interpretation information to set up a first set of multidiscipline earth model based on the same conceptual earth model (Fig. 13).

The WOG 3D software is used for picking targets from a consistent earth model. Several selection modes based on petrophysic attributes (multiple cutoffs, connexity, volumetrics and fluid circulation simulations) will be applied to determine promising geobodies in the geological model. From this selection the geologist and the reservoir engineer will define the targets as a center, main axis and tolerances.

These targets are shared between the WOG 3D and a well planning package using conventional drilling constraints (torque and drag, casing design, anticollision) to determine several reference well paths. Using the results provided by the reservoir engineer, the drilling engineer plans the minimum number of wells needed to reach all the targets.

When drilling, LWD and mud logging information will be accessed by request on both locations: rigsite and office. The preprocessed data are used to determine traces of geological feature boundaries and properties along well bore paths. This interpreted information will be shared between the WOG 3D software (Fig. 14) located on rigsite and at the office site and used to synchronize the data base used to visualize the earth model for the geologist and geophysicist engineers and the drilling engineer on both sites using either standard or 3D visualizations. From this new and interpreted information the geologist will update the earth model and change, if necessary the targets location or size.

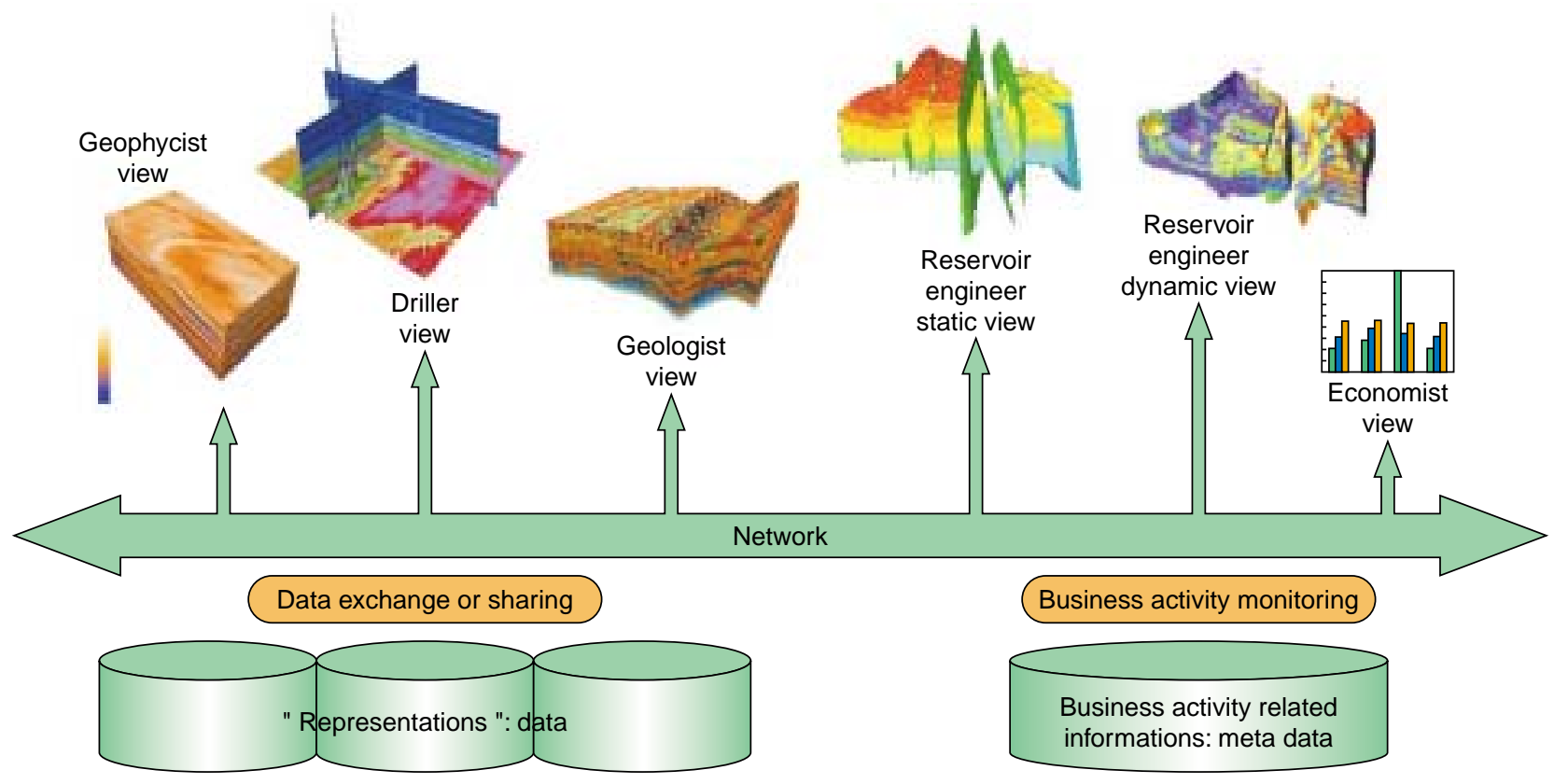

Figure 13

Data distribution through network for a sharing knowledge. 

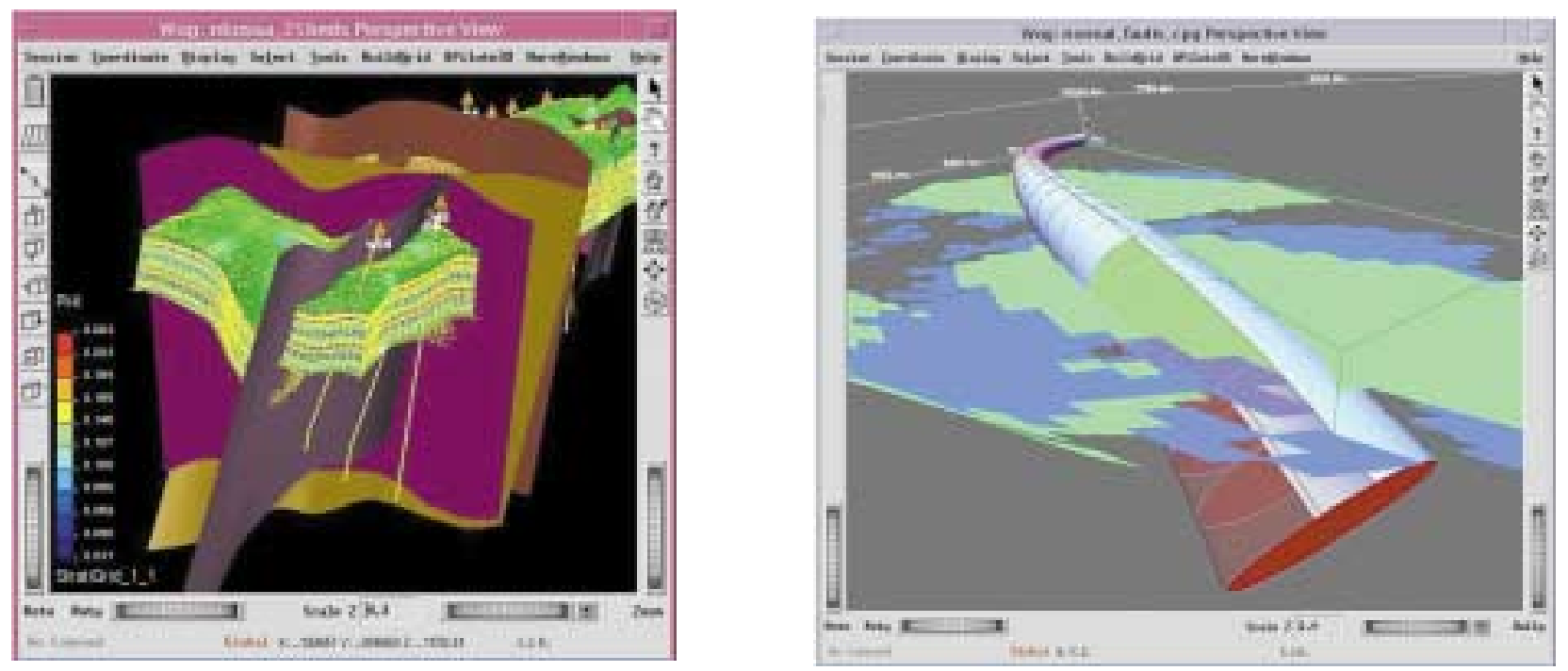

Figure 14

WOG 3D snapshots.

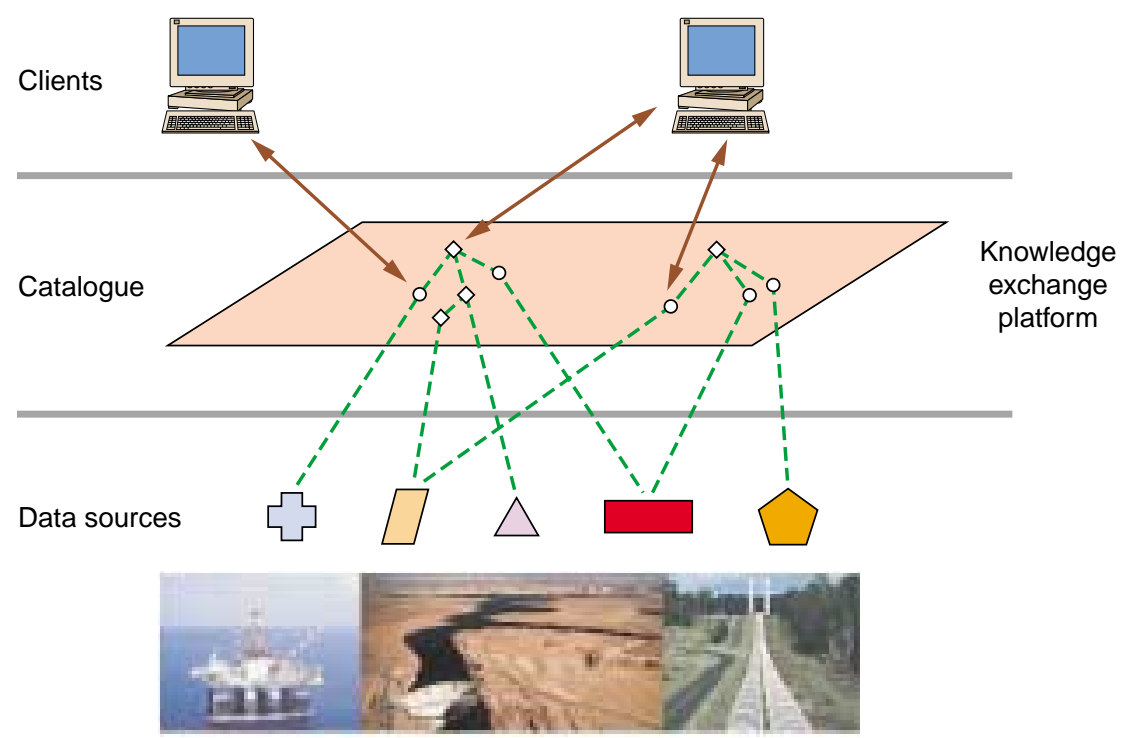

Figure 15

Episem-Action project.

While the geologist and geophysicist applications are generally connected to the network, the drilling engineer is a highly mobile user who is often operating on a PC which can be connected or disconnected from the network depending on location. This situation requires an integration strategy that allows for the drilling engineer to work in either situation. The usage is a simple connect, disconnect, reconnect sequence, but managing the data flow is quite complex. There will be a process to allow the database used by the drilling engineer to be easily resynchronised with the database updated by the geologist.

Once synchronised the drilling engineer will then be asked what he wants to do about the updated targets location such as changing the well path. IFP has a solid background on interoperability: the results of the Omega ${ }^{\mathrm{TM}}$ project and the Episem-Action project (Fig. 15). In the Omega ${ }^{\mathrm{TM}}$ project, a "1D card" was linked to every earth model entities. The objective of this project was to create services, methods and 
tools to develop interoperable 3D earth models. The EpisemAction ${ }^{\mathrm{TM}}$ project proposes a new approach to ensure collaboration between "shared earth model" applications on Internet or intranet and capitalization of value-added business knowledge. Web services are provided for managing this business knowledge on the Web with effective security between servers and applications. This enables production and management models for coping with various hypotheses and interpretations.

On the basis of these developments IFP and its partners will focus on developing procedures which will help to generate the necessary interpreted information from the measurement performed downhole (LWD) or at the surface (mud logging). One important challenge will be also to take into account the uncertainties either in the earth model or contained in the information generated while drilling. A good handling of the uncertainties will help the geologist and the drilling engineer to take the right decisions at the right time.

\section{DRILL STRING FATIGUE}

Another aspect which is very important in interactive drilling needs to be mentioned: the failure of the drill string.

Failure due to fatigue is a very costly problem in the oil and gas industry. Although, many investigators have previously addressed this problem, its frequency of occurrence is still excessive. Drill string failure occurs on $14 \%$ of all rigs and the resulting downtime costs roughly $\$ 106000$ per event [17].

Failure causes can be estimated as follows:

- fatigue is the main cause in $65 \%$ of the failures and has a significant impact in an additional $12 \%$;

- combined excessive tension and torque give failures in $13 \%$ of the cases;

- low toughness of material is mentioned for only $8 \%$ of the failures.

IFP and its partners Vallourec and Cybernetix are leading a project on fatigue management of components of the drill string. The aim of this project is to design, build and test a system which will record in each component the accumulation of fatigue as drilling operations go on. Therefore, this project is split in two main tasks. Firstly, a numerical simulation of the drillstring behavior allows stress calculation in each drillpipe and gives a fatigue damage estimation. Secondly, this predicted fatigue damage is recorded on an electronic chip encapsulated and bonded on each drillpipe. Reading and writing is performed automatically in the rig environment when the component travels through the rotary table and without any contact. Thus each component of the drill string will conserve its own fatigue accumulation insuring a continuous and accurate monitoring of its capabilities.

\section{CONCLUSIONS}

Capitalize on drilling is an efficient way to reduce cost of development and exploitation of an oil or gas field. Drilling is a unique opportunity to acquire data in order to take real time decisions leading to a global optimization of the drainage system.

Most technologies needed are available at a reasonable cost. However, they must fit within the time scale of drilling activity. They also have to interact with each other to enable decision making at crucial times.

IFP and his partners, as shown in this paper, have find solutions to some technology gaps.

In the following papers, some research projects results managed by IFP and partners are presented.

The structure of this dossier is the following:

- Intelligent Drilling Surveillance through Real Time Diagnosis

I. Rey-Fabret, JF. Nauroy, O. Vincké, Y. Peysson, I. King

(IFP), H. Chauvin and F. Cagnard (Geoservices).

- Seismic While Drilling (SWD) Techniques with Downhole Measurements, Introduced by IFP and its Partners in 1990-2000

C. Naville, S. Serbutoviez, A. Throo, O. Vincké (IFP), F. Cecconi (Geoservices).

- Geomechanical Log Deduced from Porosity and Mineralogical Content

E. Bemer, O. Vincké and P. Longuemare (IFP).

- Well Optimization by Geosteering

JF. Rainaud, O. Vincké and M. Elkouhen (IFP), M. Perrin (ENSMP) and S. Brandel (LSIIT).

\section{REFERENCES}

1 Pavone, D. (1999) Interactive Drilling for Fast Track Oilfield Developement, J. Lecourtier (ed.), Éditions Technip, Paris.

2 Pavone, D. and Desplans, J.P. (1994) Application of High Sampling Rate Downhole Measurements for Analysis and Cure of Stick-Slip in Drilling. SPE 28324.

3 Mabile, C., Pavone, D. and Desplans, J.P. (1996) A New Way of Using Surface Measurements to Detect Downhole Vibrations. SPE 36883.

4 Rey-Fabret, I., Oudin, N. and Mabile, C. (1997) Detecting Whirling Behaviour of the Drill String from Surface Measurements. SPE 38587.

5 Mabile, C., Fay, J.B. and Desloovere, O. (1997) Standard Surface Measurements Sampled at High Acquisition Rate Help in Detecting Drill String Vibrations. OMC 8997.

6 DePazzis, L., Delahaye, T., Besson, J.L. and Lombez, J.P. (1989) New Gas Logging System Improves Gas Shows, Analysis and Interpretation. SPE 19605.

7 Harris, T.W.R., Werker, R, Debray, B., Lecann, J.P. and Desloovere, O. (1997) New Delta Flow Kick Detection System Ensures Safer Drilling. OMC 2297. 
8 Naegel, M., Pradié, E., Delahaye, T., Mabile, C. and Roussiaux, G. (1998) Cutting Flow Monitor Cleaning in Extended Reach Wells. SPE 50677.

9 Roussiaux, G. and Ross, K. (1999) Cuttings Flow Meter Takes Guesswork Out of Hole Cleaning. Petroleum Engineer International.

10 Ten Haven, H.L., Arbin, P., Simon, B., Collo, G., Le Cann, J.P. and Mulero, P. (1998) Applications and Limitations of Mud Logging Gas Data in the Detection of Formation Fluids and Overpressure Examples from South East Asia. IPA Indonesia, Oct.

11 Beda, G., Quagliaroli, R., Segalini, G., Barraud, G. and Mitchel, A. (1999) A Real Time Geologic and Reservoir Interpretation Tool. SPWLA, Gas While Drilling (GWD), June.

12 Natini, F., Dini Erga-Enel, I., Certo, M., Cola-Enel, T., Soulier, L., Cecconi, F. Naville, C. and Serbutoviez, S. (2000) Seismic While Drilling Measurements in Italian Deep Geothermal Wells. WGC 2000.
13 Naville, C., Serbutoviez, S., Throo, A., Batini, F., Dini Erage-Enel, I. and Cecconi, F. (2000) Drillbit SWD Reverse Walkaway Using Downhole Reference Signal. SPE 65115.

14 Lurie, P., Head, P. and Smith, J.E. (2003) Smart Drilling with Electric Dillstring ${ }^{\mathrm{TM}}$. SPE/IADC 79886.

Jellison, N.J. and Hall, D.R (2003) Intelligent Drill Pipe Creates the Drilling Network. SPE 80454.

15 Jellison, M.J. et al. (2003) Telemetry Drill Pipe: Enabling Technology for the Downhole Internet. SPE 79885.

16 A.J. Branch et al. (2001) Real-Time Well Construction - A Case History of Sincor's Heavy Oil Project. SPE/IADC 67757.

17 Vaisberg, O., Vincké, O., Perrin, G., Sarda, J.P. and Fay, J.B. (2002) Fatigue of Drillstring: State of the Art. Oil \& Gas Science and Technology - Revue de l'IFP, 57, 1, 7-37.

Final manuscript received in July 2004 